\title{
ANÁLISIS SOBRE EL CONOCIMIENTO Y VALORACIÓN DE LA JUSTICIA INDÍGENA EN IMBABURA TRAS LA SENTENCIA N 113-14-SEP-CC
}

\author{
Magdalia Maribel Hermoza*; Hugo Bayardo Santacruz; María Belén Chuquín ${ }^{1}$ \\ ${ }^{1}$ Abogada por la Pontificia Universidad Católica del Ecuador Sede Ibarra, Escuela de Jurisprudencia. \\ *Autor para correspondencia:email: mmhermoza@pucesi.edu.ec
}

Recibido: 2017/04/04 Aprobado: 2017/31/10

DOI: https://doi.org/10.26621/XIV18.2018.06.A04.PUCESI.2550.6684

\begin{abstract}
RESUMEN
Las constituciones que el Ecuador ha tenido en su vida republicana muestran que los derechos contenidos en éstas han ido incrementándose, tanto en número como en su contenido. Sin embargo, el reconocimiento de ciertos derechos no ha dejado de ser problemático, debido a las hegemonías colonialistas que se han impregnado en el imaginario social. En este trabajo se analizan las valoraciones que tienen los integrantes de la sociedad imbabureña respecto del derecho que tienen las comunidades, pueblos y nacionalidades indígenas para administrar justicia, conforme a sus tradiciones ancestrales y su derecho propio. Con esto se pretende mostrar que la justicia indígena sigue siendo desvalorada, debido no solo a la mala prensa que se da sobre ella, sino por la injerencia que ha tenido la Corte Constitucional de Ecuador en su limitación, pues este organismo fue el que ha reprobado la facultad que tienen las autoridades indígenas para conocer determinados hechos que afectan a su convivencia comunitaria lo cual, sin duda, ha incidido para que la sociedad, en general, y los operadores jurídicos, en particular, sigan considerando a la justicia indígena por debajo del modelo de justicia ordinario.
\end{abstract}

Palabras claves: pueblos indígenas; pluralismo jurídico; derecho positivo.

\section{ABSTRACT}

The constitutions that Ecuador has had in its republican life, show that the rights contained in these have been increasing both in number and content. However, the recognition of certain rights has not stopped being problematic due to the colonialist hegemonies that have been impregnated in the social imaginary. This paper analyzes the appreciations that the members of the Imbabura society have, regarding the right indigenous communities, peoples and nationalities possess when it comes to administer justice according to their ancestral traditions and their own right. This intends to show that indigenous justice continues to be devalued, due not only to the bad press about the matter, but also because of the interference that the Constitutional Court of Ecuador has had in its limitation, since this institution has been the one that has condemnes the power that the indigenous authorities have to know certain facts that affect their community coexistence, which undoubtedly has affected society, in general, and legal operators, in particular, continue to consider indigenous justice below the model of ordinary justice.

Keywords: Indigenous peoples; legal pluralism; positive law. 


\section{INTRODUCCIÓN}

En la comunidad de La Cocha, ubicada de la parroquia de Zumbahua, de la provincia de Cotopaxi, el 9 de mayo de 2010 a eso de las 19:00 horas, mientras la comunidad se encontraba festejando una celebración, se produjo la muerte de un joven de la comunidad el cual, tras ser golpeado, fue ahorcado con una correa.

La comunidad al tener conocimiento del hecho, inmediatamente procedió a hacer las averiguaciones pertinentes consiguiendo, al día siguiente, identificar y capturar a 5 jóvenes sospechosos de la muerte del comunero, quienes después de un proceso, fueron sancionados atendiendo su grado de participación en tan lamentable hecho.

El papel que tuvieron los medios de comunicación en esta problemática ocasionó que la opinión se polarizara, tanto a favor como en contra de la forma de administración de justicia indígena. Una de las opiniones que mayor trascendencia adquirió fue la del presidente Rafael Correa quien, en sus alocuciones sabatinas, criticó airadamente las sanciones impuestas por las autoridades indígenas, señalando que lo que ahí se había llevado era una monstruosidad, pues no había existido justicia sino tortura.

Así dio inicio una enconada confrontación entre el mandatario ecuatoriano y las autoridades indígenas de la comunidad de La Cocha, hecho que llevó a que, en el plano internacional, el Relator Especial de la ONU, James Anaya, expresase su preocupación por este lamentable asunto ya que, a su juicio, los comentarios producidos no hacían más que alentar visiones racistas y discriminatorias contra el conjunto de los pueblos indígenas, resaltando que los pueblos indígenas tienen el derecho de administrar justicia, conforme lo reconoce la Constitución y los tratados internacionales.

De esta manera, desde el ámbito internacional se dejaba planteado que, a pesar de la legalidad de las actuaciones de las autoridades indígenas, había una evidente falta de coordinación, cooperación y respeto por parte de los organismos oficiales tales como: la Fiscalía, el Ministro de Gobierno y la Policía, entre otras instituciones del Estado, que apelan porque los dirigentes indígenas sean procesados conforme al debido proceso de la justicia ordinaria, por haber violado los derechos fundamentales de los 5 imputados por la muerte del comunero.

El desenlace de todo este intrincado suceso estaría lejos de presentarse, al prevalecer las apreciaciones de las autoridades del Estado y el poder punitivo se impuso sobre los derechos de los pueblos indígenas pues, efectivamente, el 4 de junio de 2010, los dirigentes de la comunidad La Cocha fueron detenidos y acusados del delito de plagio ante un juez ordinario, el cual ante la duda razonable y motivada sobre las normas jurídicas, aplicables al caso, procedió a liberar a las autoridades detenidas y elevar en consulta a la Corte Constitucional.

Por otro lado, los 5 jóvenes que ya habían sido sancionados por la justicia indígena, fueron apresados y acusados por la fiscalía del delito de asesinato, llegando a la etapa de juicio ante el Tribunal de Garantías Penales de Cotopaxi, quien el 31 de enero de 2011 decidió, por un lado, suspender la tramitación de la causa y remitir en consulta a la Corte Constitucional antes de incurrir en una vulneración del principio non bis in ídem y, por otro lado, ordenar el 12 de mayo de 2011 la liberación de los 5 detenidos con medidas sustitutivas.

El tiempo que llevó a la Corte absolver la consulta plantada fue extenso, pues sería de esperar hasta el 30 de julio de 2014 para que la Corte Constitucional de Ecuador, en la Sentencia No 113-14-SEP-CC, caso Nº 0731-10-EP, señalase que en el presente caso no se violentó el principio non bis in ídem constitucional. De acuerdo al criterio de la Corte Constitucional ecuatoriana, la justicia indígena sancionó en su debido momento, atendiendo los efectos sociales que ese hecho produjo en la comunidad, mientras que la actuación de la justicia ordinaria lo estaba haciendo atendiendo a la lesión de la bien jurídica vida. El desenlace de esta cuestionable distinción, determinó que la Corte constitucional límite la competencia a la jurisdicción indígena y conceda a la justicia ordinaria, la competencia para atender todos los hechos que atenten contra la vida de las personas, dentro de los territorios de los pueblos y nacionalidades indígenas. 


\section{Planteamiento del problema}

la Constitución ecuatoriana de 2008, avanzando lo que la anterior constitución del 1998 había logrado, en su artículo 171 reconoció la diversidad cultural y las jurisdicciones de las comunidades, pueblos y nacionalidades indígenas, fundadas en sus tradiciones ancestrales y su derecho propio, dentro de su ámbito territorial y con garantía de la participación de la mujer indígena. Se resaltó, además, que las decisiones de la jurisdicción indígena deberán ser respetadas por las autoridades públicas, las mismas que están en la obligación de no interferir en las decisiones de las autoridades indígenas que actúen en el ejercicio de la función jurisdiccional conferida.

De este reconocimiento se desprendía que las resoluciones tomadas por las autoridades indígenas tenían el carácter de definitivas, siendo improcedente que otra autoridad pueda revisarlas o infringirlas pues, de hacerlo, se estaría irrespetando el principio non bis in ídem reconocido en el art. 76.7 letra "i", de la Constitución ecuatoriana, el cual expresamente señala que: «Nadie puede ser juzgado más de una vez por la misma causa y materia. Los casos resueltos por la jurisdicción indígena deberán ser considerados para este efecto». Referencia que igualmente es recogida tanto en el art. 344, letra "c" del Código Orgánico de la Función Judicial, como en el art. 4.9 del Código Orgánico Integral Penal, el cual con meridiana claridad establece la prohibición de doble juzgamiento en los casos en que éstos hayan sido resueltos por la jurisdicción indígena.

Sin embargo, la Constitución ecuatoriana, así como las demás constituciones de su entorno jurídico, delegó al poder legislativo la tarea de crear una ley que establezca los mecanismos de coordinación y cooperación entre las jurisdicciones indígena y ordinaria, fijando especialmente los límites, las competencias y las formas de cómo éstas han logrado una cooperación mutua. No obstante, esto ha quedado como una tarea pendiente de la Asamblea Nacional, la cual no ha logrado pasar del debate a la promulgación de una ley que trate adecuadamente esta problemática.

A falta del interés de crear los mecanismos de coordinación entre la justicia oficial y la indígena, la Corte Constitucional ecuatoriana, por las atribuciones que le confiere la Constitución en el art. 436.7, ha sido el organismo que tímidamente ha dado respuesta a esta cuestión mediante un reducido número de sentencias que han sentado un precedente en el país, no por lo positivo de sus apreciaciones, sino por las limitaciones que se han impuesto al ejercicio de la jurisdicción indígena.

En efecto, la Corte Constitucional de Ecuador poco ha contribuido en la construcción del pluralismo jurídico igualitario que se pensaba que ésta podía promover, toda vez de que la Corte estableció una serie de normas que, en definitiva, resaltan el rol secundario que tiene la justicia indígena frente a la justicia ordinaria al señalar que: «[l]a jurisdicción y competencia para conocer, resolver y sancionar los casos que atenten contra la vida de toda persona, es facultad exclusiva y excluyente del Sistema de Derecho Penal Ordinario [...]» ${ }^{1 .}$

\section{MATERIALES Y MÉTODOS}

El presente trabajo recoge un estudio socio jurídico sobre los efectos que ha tenido la limitación de la administración de la justicia indígena en el imaginario social de los habitantes de los cantones de Otavalo, Cotacachi, Antonio Ante, Ibarra, Urcuquí y Pimampiro de la Provincia de Imbabura. Para ello, en un primer momento, se realizó una investigación documental-bibliográfica con el propósito de realizar un análisis retrospectivo del Caso "La Cocha", que fue tratado por los jueces de la Corte Constitucional del Ecuador mediante la Sentencia No 113-14-SEP-CC, caso Nº731-10-EP.

Para contrastar los efectos que ha derivado la mencionada sentencia en el imaginario social de la población imbabureña, se recurrió al uso de encuestas personales, debidamente validadas, tanto a la población indígena como mestiza de los distintos cantones. Por medio de la información proporcionada por esta herramienta, se pretendió analizar cuál era la actual percepción social que existe en torno a la justicia indígena, luego de que ésta fuera limitada por la Corte Constitucional del Ecuador. 


\section{Muestra y variables de investigación}

al estar involucrada la cosmovisión que mantienen las comunidades indígenas, el tipo de investigación aplicada fue de índole descriptivo. De hecho, para identificar a la población, materia de este estudio, se recurrió a los datos proporcionados por el Instituto Nacional de Estadísticas y Censos (INEC) el cual, según el censo poblacional del año 2010, señala que en el cantón Otavalo existen 181.175 habitantes; en el cantón Cotacachi, 40.036 habitantes; en el cantón Antonio Ante, 43.518 habitantes; en el cantón Ibarra, 104.874 habitantes; en el cantón Pimampiro, 12.970 habitantes; y en el cantón Urcuquí, 15.671 habitantes.

Con los datos obtenidos se tiene que el universo total de la población de la provincia de Imbabura es, aproximadamente, 398224 habitantes, dato que en definitiva serviría para determinar el tamaño de la muestra de acuerdo a la siguiente fórmula:

$$
n=\frac{N o^{2} Z^{2}}{(N-1) e^{2}+o^{2} Z^{2}}
$$

\section{Donde:}

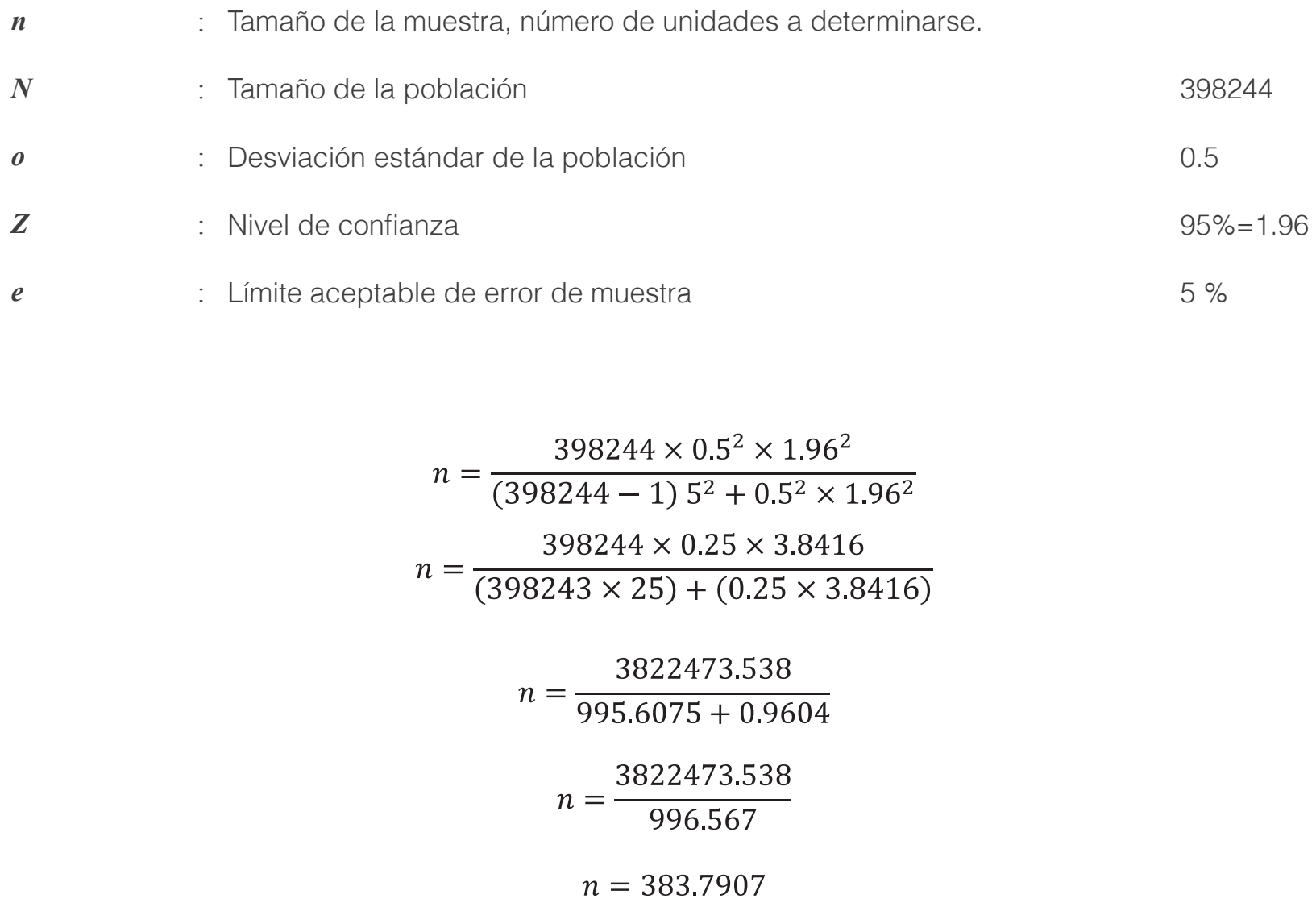




\section{RESULTADOS Y DISCUSIÓN}

\section{Análisis estadístico descriptivo}

Numerosas investigaciones coinciden en señalar que en América Latina, desde las postrimerías del siglo XX y principios del siglo XXI, existe un surgimiento de las etnias originarias (Stavenhagen, 1990; Sanchez, 2002; Brandt y Valdivia, 2006, 2007). En Ecuador, a partir de la emergencia indígena, los movimientos indígenas tomaron un verdadero protagonismo político, con un discurso que resaltaba las diferencias culturales que ellos tenían, respecto de la sociedad dominante que los discriminaba.

A partir de ahí, comenzó a darse un prometedor avance en cuanto al reconocimiento de un nuevo sujeto colectivo de derecho: los pueblos indígenas (Sanchez, 2002). Quizá el derecho que más visibilidad adquirió fue el de la jurisdicción indígena, debido a que su reconocimiento confrontaba a la cultura jurídica dominante la cual, desde su importación, negó cualquier aporte que pudiera provenir de los sistemas normativos de los pueblos indígenas (Zaffaroni, 2000).

Transitadas casi dos décadas del reconocimiento del pluralismo jurídico, se consideró pertinente analizar si la población Imbabureña tenía conocimiento de que, las formas de resolución de conflictos internos, por parte de las comunidades indígenas, era un sistema de justicia equiparable al sistema de justicia ordinario. Los resultados de este cuestionamiento mostraron que el $70 \%$ de la población era consciente de la vigencia que tiene la justicia indígena. Sin embargo, a nivel particular se constató que, en los cantones donde existe una mayor incidencia poblacional indígena, la justicia indígena es conocida con mayor amplitud. Para el caso de Cotacachi, que cuenta con una población indígena de 16.235 personas, el porcentaje de conocimiento de la justicia indígena es del 80\%, mientras que, para el cantón de Otavalo, que tiene una población indígena de 60.032 habitantes, la cifra aumenta en seis puntos porcentuales, ubicándose en 86\%.(Figura 1.)

Figura 1. Conocimiento de la justicia indígena

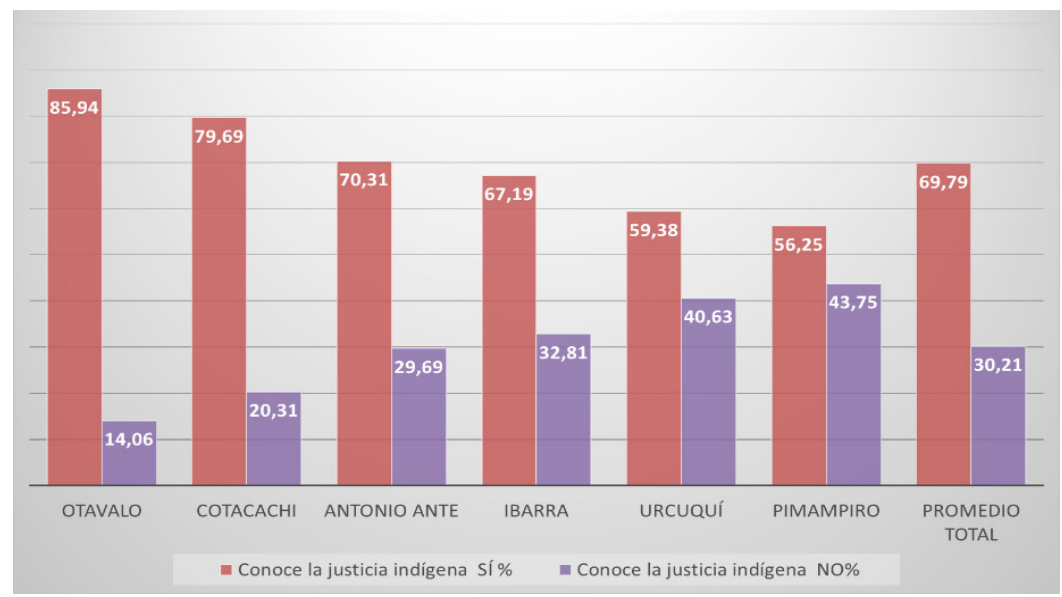

La proporción de habitantes indígenas en cada cantón es un factor que incide en el conocimiento de las formas de sanción asociadas a la justicia indígena. De hecho, se pudo notar que el conocimiento de la justicia indígena y las sanciones que ésta implica, guarda relación con la aceptación o el rechazo que la sociedad tiene respecto de la justicia indígena. Así, pues, en los cantones que tienen un porcentaje significativo de población indígena, existe una mayor aceptación de las sanciones que se aplican en la justicia indígena, en contraposición de aquellos que cuenta con una población indígena menor, donde existen algunos reparos a la hora de aceptar a la justicia indígena, como un instrumento válido para solucionar las controversias (Figura 2.). 
En tal virtud, de los datos obtenidos se colige que, si bien no existe una aceptación total, el porcentaje alcanzado es muy representativo ya que, de modo general, la población Imbabureña acepta la aplicación de las sanciones de la justicia indígena en un 66\%.(Figura 3)

Figura 2. Aceptación o rechazo de penas

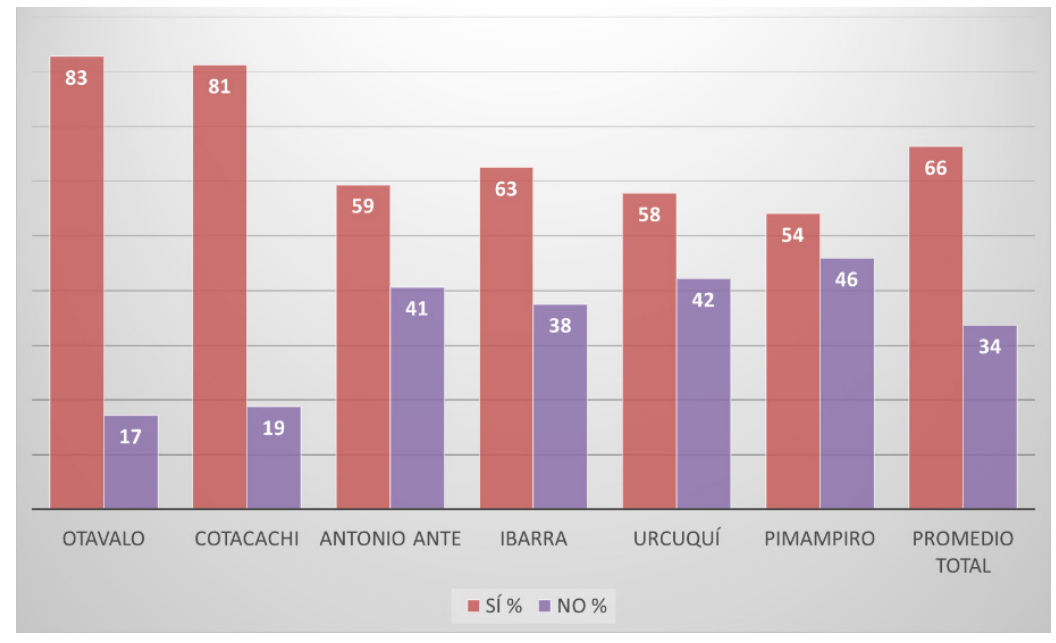

Cabe mencionarse que esta aceptación se la formula a pesar de que las sanciones no son conocidas de forma directa dado que, de los datos consignados, se desprende que aproximadamente la mitad de los encuestados no ha presenciado el procedimiento que siguen las autoridades indígenas para la imposición y ejecución de sanciones impuestas.

Figura 3. Presencia de aplicación de justicia indígena

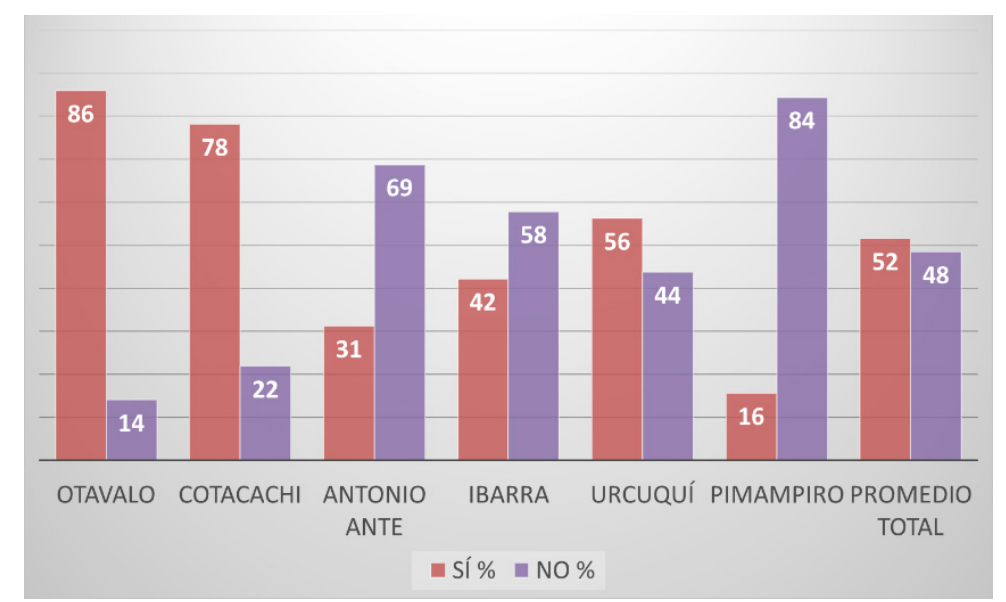

La falta de conocimiento de la justicia indígena es un elemento clave que incide en su valoración. De hecho, se constató que, a nivel provincial, a pesar de señalarse reiteradamente que la justicia indígena es restaurativa, la población en un amplio porcentaje la relaciona con los castigos físicos (43\%). Sin embardo, se debe resaltar que esta variable en los cantones de Otavalo y Cotacachi no es mayoritaria, dado que en estos dos cantones existe una concepción que relaciona a las sanciones con las formas de purificación ancestral (Figura 4). 
Figura 4. Aspectos de la justicia indígena

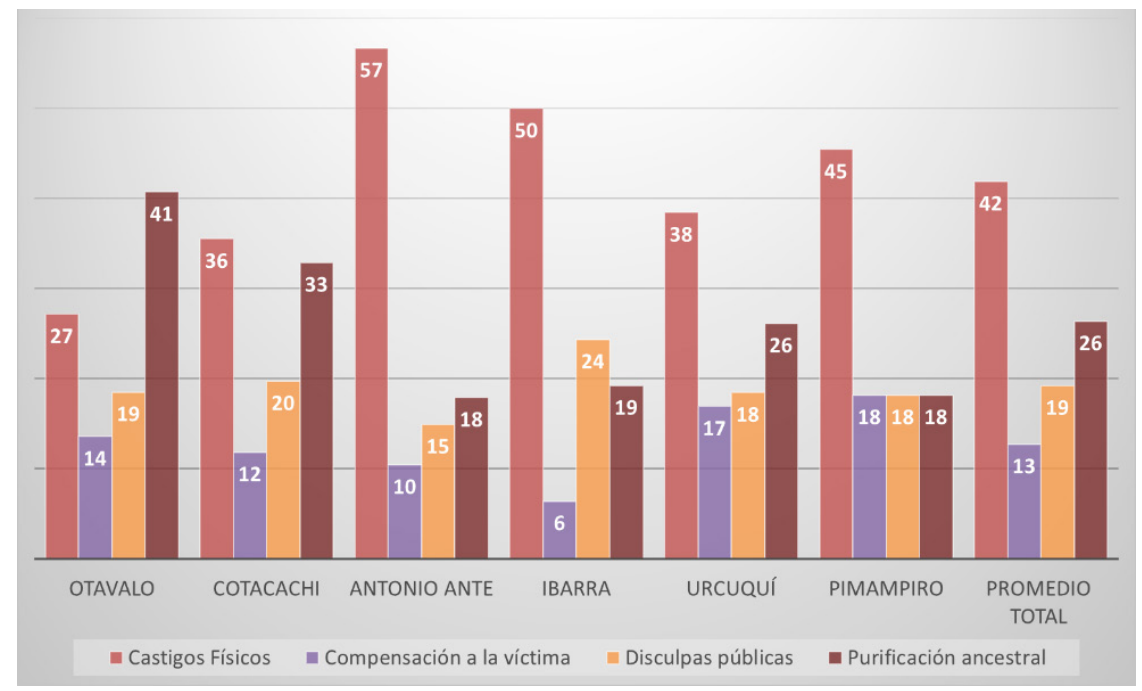

En lo que atañe a la percepción de la efectividad de la justicia indígena, se aprecia que en el imaginario social ésta es inefectiva, dado que la opinión dominante es que no se ajusta a la realidad actual. Los encuestados en los distintos cantones, si bien manifiestan que la justicia indígena sirve para resolver controversias, afirman que es un modelo que no se adecua a la compleja problemática que agobia a la sociedad. Por ello es que, incluso en los cantones que tienen una población indígena significativa, se tiende a considerar al sistema de justicia indígena como poco efectivo ante la realidad actual. Así, el cantón que lo califica como excelente en mayor porcentaje es Cotacachi y éste apenas llega al 23\%. Como modelo bueno, por debajo del 20\%, los cantones Pimampiro, Urcuquí y Otavalo. Como un modelo que no se ajusta a la realidad actual expresan en mayor porcentaje los cantones de Ibarra y Antonio Ante (Figura 5).

Figura 5. Evaluación de efectividad

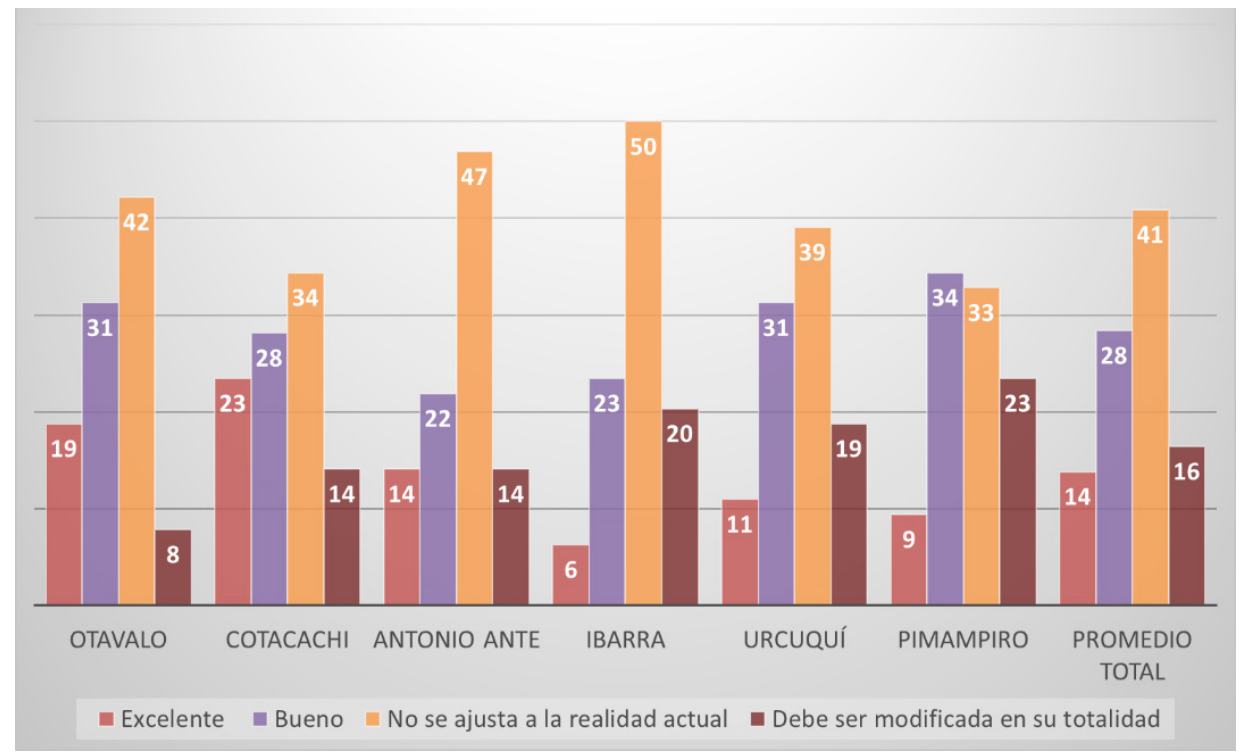


Por otra parte, al cuestionar si la justicia indígena es efectiva, en el sentido de ajustarse a los tiempos actuales, las opiniones fueron divididas. Así pues, se puede colegir que las opiniones dominantes tienden a considerar que la justicia indígena no se ajusta a la realidad actual. De hecho, se puede apreciar que, a nivel provincial, la acepción del modelo de administración de justicia indígena en cuanto a su efectividad es negativo.

Figura 6. Reincidencia por delitos cometidos en las comunidades mediante justicia ordinaria

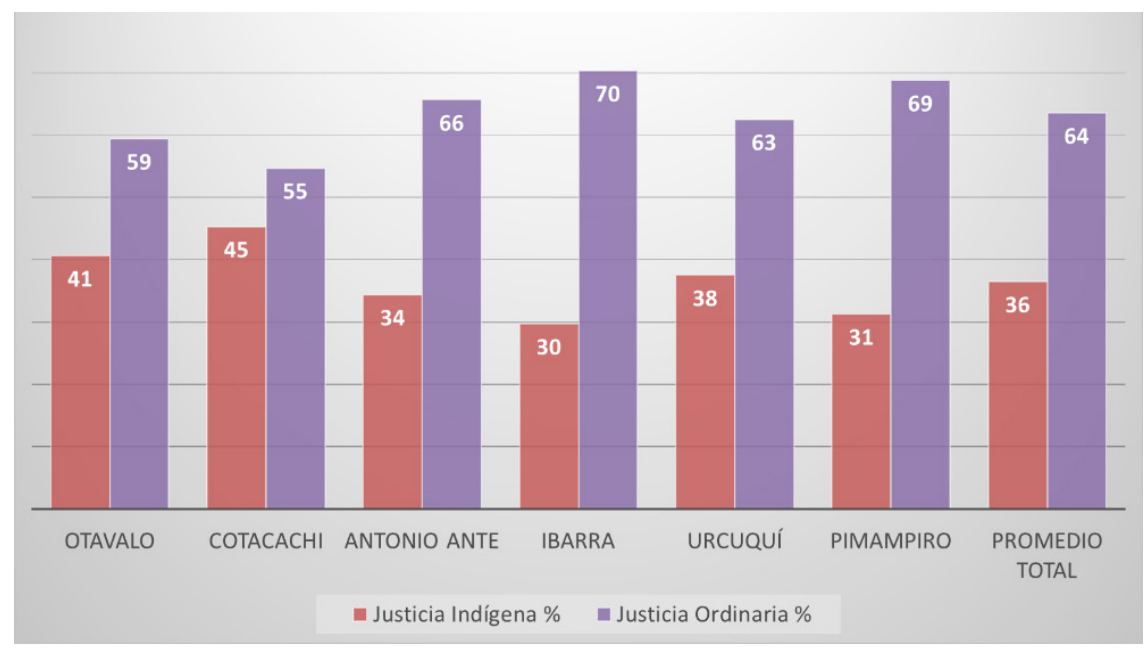

Se ha señalado que, frente a los casos de reincidencia la justicia indígena, se debe desistir de su accionar y dejar que la justicia ordinaria tome la iniciativa sancionatoria en esos asuntos. La razón no se deriva del incumplimiento de las funciones que debía haber cumplido la sanción, sino más bien a la gravedad de la pena que merece quien reincide (Figura 6). De hecho, el criterio de la población imbabureña, frente a casos de reincidencia en las comunidades indígenas, es que la justicia ordinaria ejerza la competencia en estos casos, no porque ésta sea más efectiva, sino porque las penas que ella aplica son más severas que las impuestas por las autoridades indígenas (Figura 7).

Figura 7. Severidad de las penas del COIP

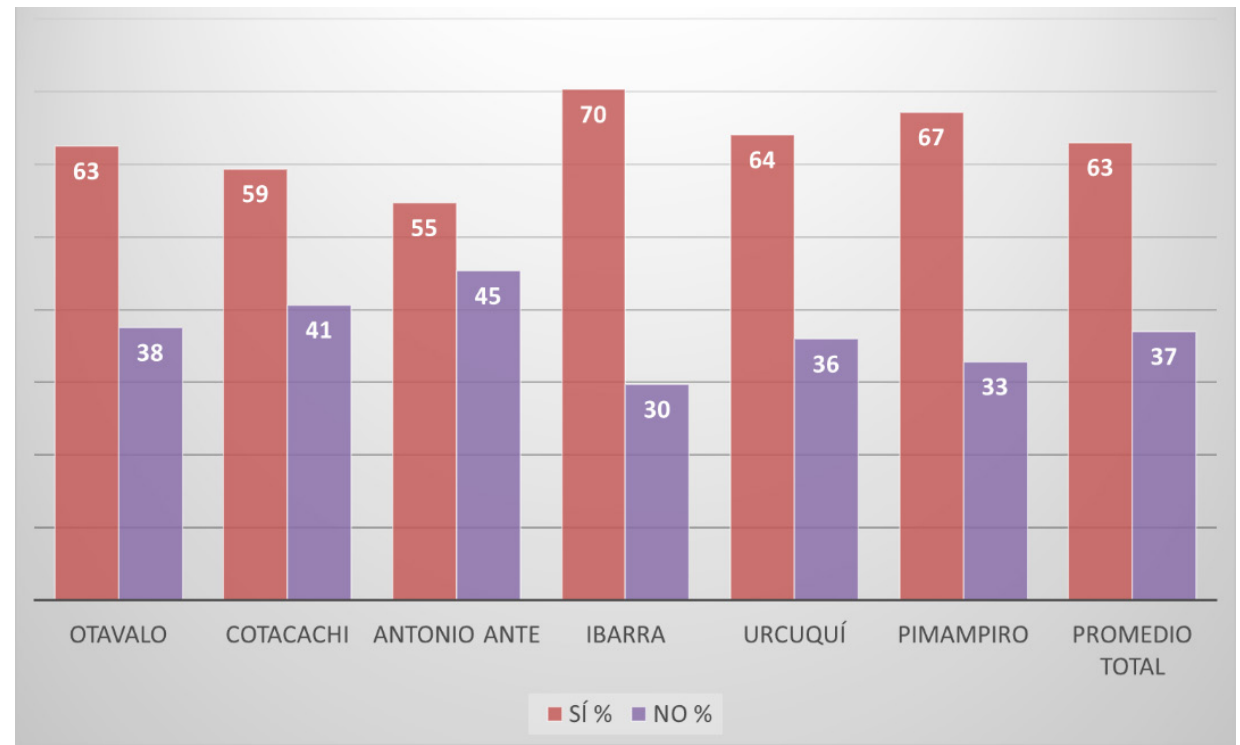


Al apreciar a la justicia ordinaria como más severa frente a los delitos cometidos, resulta lógico que la sentencia de la Corte Constitucional resulte completamente aceptada por la sociedad en general. De hecho, la población Imbabureña ha mirado con buenos ojos, y con una aceptación elocuente, que la jurisdicción indígena se límite a resolver controversias menores, mas no de aquellos delitos que comprometen el bien jurídico vida (Figura 8).

Figura 8. Intervención de la justicia ordinaria en delitos que atentan la vida

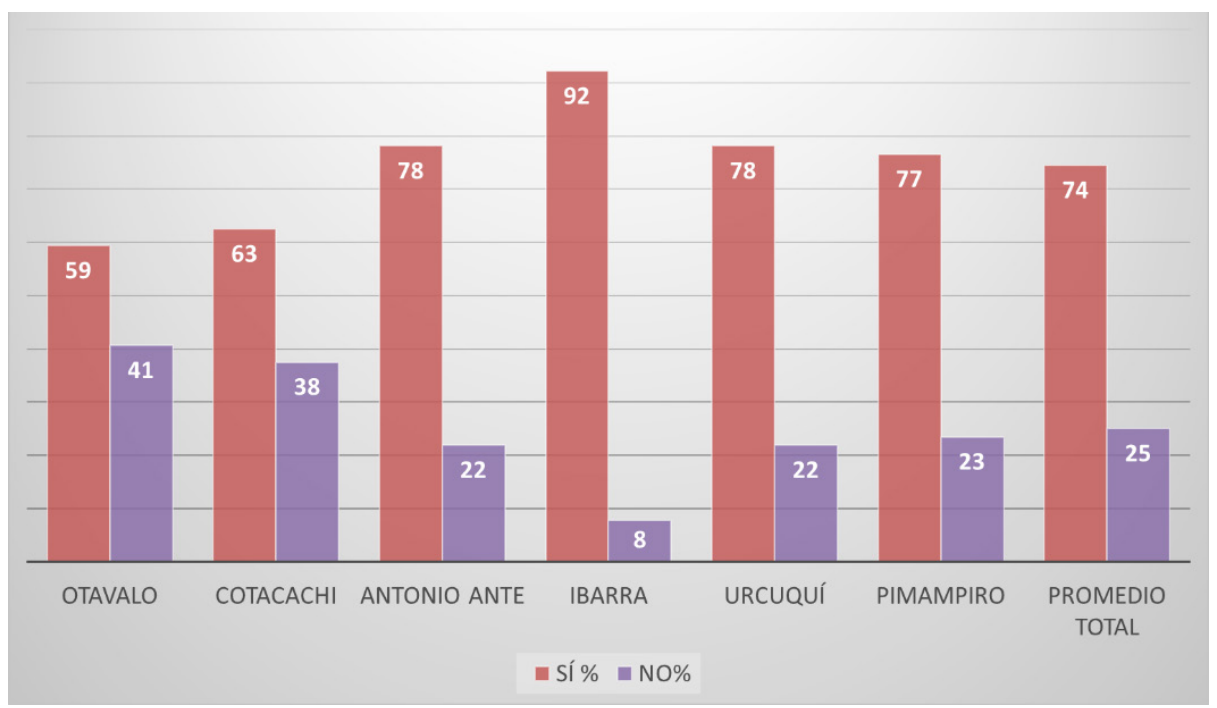

Apartados los delitos contra la vida y aquellos que pueden considerarse como graves, la sociedad imbabureña coincide en que prevalezca el principio nom bis in ídem. En efecto, el 75\% de la población de los distintos cantones de la provincia, manifiesta que la justicia ordinaria no debería intervenir si la justicia indígena ya ha conocido y resuelto el caso. Reconocen a la administración de justicia indígena en igual jerarquía que el sistema ordinario, por lo que una segunda intervención, en una misma causa, iría en contra del principio señalado en la norma suprema y demás legislación secundaria que señala que nadie será juzgado dos veces por la misma causa (Figura 9).

Figura 9. Violación principio non bis in ídem

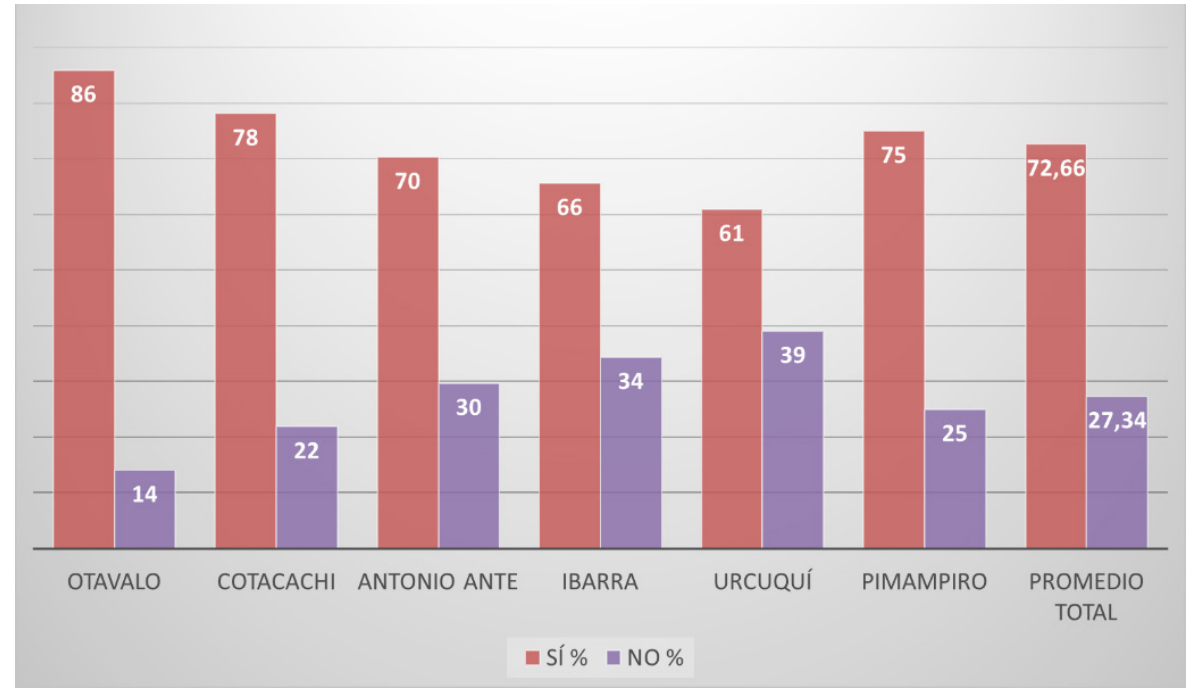




\section{CONCLUSIONES}

De los datos obtenidos, se puede concluir señalando que la sentencia de la Corte Constitucional de Ecuador, al quitar competencia a la justicia indígena respecto de los delitos contra la vida de las personas, asentó un precedente negativo en razón de que, implícitamente se da a entender que esta forma de justica es incapaz de dar solución a hechos de significativa gravedad.

Las encuestas aplicadas muestran que, a nivel provincial, alrededor del 70\% de la población, tanto indígenas como mestizos, tiene conocimiento de la justicia indígena. Pero este conocimiento no es respecto de los procesos que las autoridades indígenas emplean para la solución de conflictos sino, más bien, a las formas de sanción, pues gran parte de los encuestados relacionan castigos físicos con justicia indígena.

Y es precisamente en los castigos físicos donde los encuestados tienden a direccionar su percepción. De hecho, la falta de conocimientos reales sobre la justicia indígena hace que la gente considere que esta forma de justicia, no se ajusta a la realidad actual dado que, en el imaginario social, se considera que la justicia indígena es un modelo anquilosado en el tiempo y que la justicia ordinaria es lo más adecuado para reprimir los delitos.

En el estudio queda en evidencia que, ante la inseguridad social, la ciudadanía busca una represión más dura de las conductas desvaloradas. En este sentido, se aprecia que los encuestados, frente a los delitos que entrañan mayor gravedad, consideran que es mejor la privación de libertad que la aplicación de una sanción impuestas por autoridades indígenas. Es más, frente a los delitos que atentan contra la vida, la ciudadanía imbabureña se decanta por la jurisdicción de la justicia ordinaria. Sin embargo, los porcentajes también indican que gran parte de la población encuestada cree que, no debería intervenir el sistema ordinario, cuando la jurisdicción indígena se encuentra actuando; pero esto con una salvedad, ya que las informaciones recabadas mencionan que, en casos de reincidencia, deberían ser los jueces ordinarios quienes resuelvan los diferentes casos, sin importar que la jurisdicción le pertenezca a otro sistema de administración de justicia.

\section{REFERENCIAS BIBLIOGRÁFICAS}

Anaya, S. (2005) Jame: Los pueblos indígenas en el derecho internacional. Traducción de la segunda edición. Editorial Trotta. Universidad Internacional de Andalucía. Madrid.

Brandt, H, y Valdivia, R. (2006). El tratamiento de conflictos. Un estudio de actas en 133 comunidades. Lima: Instituto de Defensa Legal.

Brandt,H. y Valdivia, R. (2007). Normas, valores y procedimientos en la justicia comunitaria. Estudio cualitativo en comunidades indígenas y campesinas en Ecuador y Perú. Lima: Instituto de Defensa Legal.

Sanchez, B. (2002). Los derechos indígenas en las Constituciones de Colombia y Ecuador. En: Constitución y derechos indígenas. Jorge González (Coord.) Instituto de investigaciones jurídicas, Universidad Autónoma de México

Stavenhagen, R. (1990). "Derecho Consuetudinario Indígena en América Latina": En: Entre la Ley y la Costumbre. El Derecho consuetudinario indígena en América Latina. Rodolfo Stavenhagen y Diego Iturralde Comp. Instituto Indigenista Interamericano e Instituto Interamericano de Derechos Humanos. México.

Zaffaroni, E. (2000). Códigos penales de los países de América Latina. México: Suprema Corte de Justicia de la Nación. 